\section{EN TORNO A LA REALIDAD HUMANA EN XAVIER ZUBIRI}

\author{
Ricardo Espinoza Lolas \\ Pontificia Universidad Católica de Valparaíso \\ respinoz@ucv.cl \\ Pamela Soto García \\ Pontificia Universidad Católica de Valparaíso \\ pamela.soto@ucv.cl
}

Cómo citar este artículo/Citation: Espinoza Lolas, R. y Soto García, P. (2016). En torno a la realidad humana en Xavier Zubiri. Arbor, 192 (780): a3XX. doi: http://dx.doi.org/10.3989/ arbor.2016.780n 4005

Recibido: 25 julio 2014. Aceptado: 01 septiembre 2015.

RESUMEN: Este artículo indaga acerca del carácter de la realidad humana y su relación al concepto de persona en el pensamiento de Xavier Zubiri (1898-1983). La metodología de análisis consiste en revisar el carácter de la realidad humana desde la noología, esto es, la última etapa de la obra del autor, a fin de presentar al hombre desde su dimensión eminentemente física y siempre encarnada de la realidad humana, permitiendo repensar desde una perspectiva física el desarrollo individual, así como también, el despliegue social e histórico del ser humano.

PALABRAS CLAVE: Zubiri; realidad; persona; absoluto; noología.

\section{ABOUT HUMAN REALITY IN XAVIER ZUBIRI'S PHILOSOPHY}

Copyright: (c) 2016 CSIC. Este es un artículo de acceso abierto distribuido bajo los términos de la licencia Creative Commons Attribution (CC BY) España 3.0.
ABSTRACT: This article inquires into the nature of human reality and its connection to the concept of person in the philosophy of Xavier Zubiri(1898-1983). The methodology of the analysis consists in reviewing the nature of human reality through the prism of noology, i.e., the final period of this author's work, in order to introduce man from its always incarnate, prominently physical, dimension of human reality. This allows individual development and the historical and social display of the human being from a physical perspective to be represented.

KEYWORDS: Zubiri; reality; person; absolute; noology. 


\section{INTRODUCCIÓN}

Uno de los problemas fundamentales que piensa una y otra vez Xavier Zubiri es el problema del hombre (Gracia, 2003). Este problema moviliza la investigación del autor durante décadas -desde los años 20 a los 80 (Corominas y Vicens, 2006); tras el paso de estos largos años el filósofo va reflexionando acerca del problema del hombre desde distintas dimensiones: epistemológica, histórica, teológica y, también, desde una dimensión de orden antropológico, que se actualiza completamente desde la novedad de su pensamiento llamado "noológico», al final de su vida (Bañón, 1999). En esta dimensión el problema acerca del hombre aparece en y por sí mismo, es decir, el hombre en su carácter meramente real, que en palabras zubirianas consiste en lo propio de la realidad humana y ésta se da y se impone a la aprehensión primordial de cada uno de nosotros (Pintor Ramos, 1993). Este carácter humano a su vez es susceptible de ser descrito; descripción imperfecta pero a la vez siempre mejorable ad infinitum. Incluso, podemos decir, y sabiendo que exageramos en lo que decimos: la propia metafísica de Zubiri en torno a la «realidad», y luego su noología en torno a la «formalidad de realidad», surgen para dar cuenta de modo acabado a la pregunta por la realidad humana.

El carácter noológico de su pensamiento responde a la última etapa de la obra de Xavier Zubiri y éste resulta clave para el desarrollo de la presente investigación, pues a partir de la noología, y en especial a partir del vínculo que a través de ésta se establece con la técnica (González, 2010) es que resulta posible estudiar la articulación originaria que se dan entre intelección (hombre) y lo inteligido (las cosas). Y, precisamente, en esta articulación que se produce una aprehensión de lo real, por parte del ser humano, que permite incluso su propia viabilidad (Gracia, 1986; Guzmán, 1984).

La noología además opera de modo ejemplar en el tema de la religación haciéndose cargo de lo real mismo como modo existencial que da sentido a la propia realidad humana; realidad que siente lo real desde un "más» inespecífico que la requiere a ella misma para hacerse cargo de sí y de la totalidad. Zubiri es muy claro en esto: “(...) ¿es lo mismo metafísica y ontología? ¿Es lo mismo realidad y ser? Ya, dentro de la fenomenología, Heidegger atisbó la diferencia entre las cosas y su ser. Con lo cual la metafísica quedaba para él fundada en la ontología. Mis reflexiones siguieron una vía opuesta: el ser se funda en la realidad. La metafísica es el fundamento de la ontología. Lo que la filosofía estudia no es ni la objetividad [Husserl y su fenomenología] ni el ser [Heidegger y su ontología], sino la realidad en cuanto tal. Desde 1944 mi reflexión constituye una etapa: la etapa rigurosamente metafísica" (Zubiri, 2004, pp. 14-15).

Zubiri deja claro en el "Prólogo» que realizó para la edición inglesa de Naturaleza, historia y Dios (uno de los pocos pasajes en el que Zubiri habla de sí mismo) el carácter metafísico de su pensamiento, sin embargo, es precisamente su metafísica la que se abre a un nuevo modo de pensar, pues él filósofo hace referencia a través de su obra de un tipo de metafísica de orden fenomenológico, que se denominará como «noología».

Esta noología a la que hace referencia el filósofo se hace cargo de las cosas mismas y no deja nada fuera de ella, es decir, el carácter físico de las cosas reales no es reducido, ni puesto en "epoché», sino que es parte esencial de la propia descripción que se impone en la aprehensión humana. Por eso este carácter físico que mienta no solamente lo real, sino radicalmente al acto intelectivo o lo que nuestro pensador llama «noergia», pues si queremos hablar en la terminología del «noein» para expresar la intelección, hay que decir que este "noein» no intelige de modo intencional, sino de modo físico: “... el noein es un ergon y por esto su estructura formal es Noergia" (Zubiri, 1983, p. 94). De modo que esta intelección desde lo físico permite pensar la realidad a partir de nuevas coordenadas, y en especial en el caso de Zubiri pensar la realidad humana desde dos de sus conceptos claves: persona y cuerpo, desde un marco teórico noológico centrado en lo que él llama "formalidad de realidad" (Espinoza, 2014; Pintor Ramos, 1994a; Ferraz, 1994).

$Y$ es precisamente este marco noológico el que nos permitirá responder, a través de este artículo, alguna de las siguientes preguntas: ¿Por qué el problema del hombre es «el» problema para Zubiri? ¿Por qué el hombre es un problema fundamental para el siglo XX (y a lo mejor también en el XXI)? ¿Por qué el hombre se vuelve problema a comienzos del siglo XX? ¿Por qué sigue siendo problema el hombre todavía hoy a comienzos del siglo XXI? ¿Por qué el hombre es el tema de nuestro tiempo? ¿Por qué el hombre es la clave o nodo desde dónde se entiende la naturaleza, la historia y hasta Dios mismo o su ausencia para Zubiri? ¿Qué sucede hoy en día que todavía no podemos dar del todo con una conceptualización más acabada que dé cuenta del hombre en su complejidad? ¿Qué pasa con el hombre? ¿Cuánto puede el hombre? 
Xavier Zubiri es muy claro cuando define, en El hombre y Dios, lo propio del hombre de la siguiente manera y junto con ello es muy técnico y preciso a nivel conceptual: "Es que el hombre no sólo tiene realidad, sino que es una realidad formalmente "suya", en tanto que realidad. Su carácter de realidad es "suidad». Es lo que, a mi modo de ver, constituye la razón formal de persona. El hombre no sólo es real, sino que es "su» realidad. Por tanto, es real "frente a» toda otra realidad que no sea la suya. En este sentido, cada persona, por así decirlo, está «suelta» de toda otra realidad: es «ab-soluta» (...) Pero sólo relativamente absoluta, porque este carácter de absoluto es un carácter cobrado'" (Zubiri, 1988, p. 373). Este texto tan riguroso y algo árido es un texto que para ser entendido de modo correcto es necesario conocer, por una parte, la trayectoria filosófica del autor y, por otra, la etapa noológica de su investigación final. El texto es parte del ya célebre Curso de Roma (impartido en la Universidad Gregoriana) del año 1973, esto es, estamos ante un filósofo maduro (tiene 75 años) a tan sólo diez años de su muerte (Zubiri murió en 1983). El pensador español a esta altura de su vida estaba transitando desde su «metafísica», en donde la obra fundamental es Sobre la esencia (1962) y su concepto clave es precisamente la «esencia o la realidad como esencia» (Zubiri, 2008a) a una filosofía de la intelección, cuya obra fundamental es la Trilogía de la Inteligencia sentiente editada por Alianza en tres volúmenes entre los años 1980-1983 (Inteligencia sentiente en 1980; Inteligencia y logos en 1982; Inteligencia y razón en 1983). En esta gran obra su concepto clave es la «actualidad o la realidad como actualidad».

No está demás señalar que el término «actualidad», tan primordial en el último Zubiri (Pintor Ramos, 1994b), puede ser rastreado en el pensamiento de Heidegger. En el año 1930, Heidegger dictó su gran conferencia De la esencia de la verdad (publicada luego recién en 1943); que inaugura el cambio de orientación de lo más propio de su pensamiento, el giro (Khere), como el mismo Heidegger lo llama, al interior de su reflexión y que nos lleva del hombre al ser mismo (esa radical concepción del ser que no pudo dar a luz en Sein und Zeit de 1927) por medio de la verdad. La verdad entendida en este nuevo pensamiento como Lichtung y Unverborgenheit (idea que está presente en todo el pensamiento heideggeriano posterior a 1927) trae la idea de que son las mismas cosas las que nos permiten juzgar acerca de ellas. Nuestros juicios serán «verdaderos» porque de antemano la cosa "verdadea» ante el hombre; está presente ante él (Heidegger, 1996). La cosa porque se da como "presente» es porque puede ser "re-presentada» en el juicio. Esto es, la verdad como conformidad o adecuación reposa en algo anterior que la constituye; y esto es propio de la cosa en cuanto a su carácter de presentarse.

Esta última navegación por la realidad del pensador Xavier Zubiri es, en cierta forma, un volver a sus inicios, pero a la altura de los tiempos, sus tiempos (los años $80)$, esto es, a la altura de su propia y madura conceptualización filosófica. En este volver atrás, empero desde lo que se es ahora, Zubiri retoma desde el concepto de actualidad lo mejor de su estancia en la fenomenología de Husserl y de la ontología de Heidegger (formalmente sus maestros, junto a Ortega), porque para su pensamiento: "Actualidad es estar presente desde sí mismo por ser real" (Zubiri, 1980, p. 159).

Esto permite que el concepto de "actualidad" se presente en oposición a la mera representación (Vorstellung), en cuanto, presencia efectiva (Cerezo, 1996) no añade ninguna nota específica a la realidad, de modo que el término "actualidad» está pensado de forma radical la realidad desde un modo noológico en cuanto se la entiende como estar presente en cuanto está presente en y por sí mismo como real (Espinoza, 2014). Este último Zubiri permite ver las huellas de ese carácter físico somático de los conceptos que el pensador ya utilizaba a comienzos de los años 30; nos referimos a los cursos que dictó en Madrid y Barcelona; a los primeros artículos y conferencias que dicta, y que posteriormente rescata en Naturaleza, Historia, Dios de 1944. “... Zubiri antes de la publicación (1944) de su primer libro Naturaleza, Historia Dios ya pensaba desde el problema mismo de la unidad del hombre y siempre veía que el hombre es corporal y desde ese carácter natural deberíamos pensar su trascendencia, su alma, etc. Se tenía que mostrar más que una dialéctica entre cuerpo y alma, más que un alma sustancial inmortal que está 'dentro' del cuerpo material y corruptible, una cierta unidad de 'emergencia' del alma desde el cuerpo, pero no sabía del todo cómo pensarlo sin las herramientas conceptuales de la filosofía" (Ascorra y Espinoza, 2011, p. 1064)

En este mismo registro es interesante tener presente el bello y profundo curso de invierno del semestre 34-35 titulado Helenismo y cristianismo, el cual entre los años 1937 al 1939 fue profundizado por el filósofo a partir de los cursos dictados en el Círculo de Estudios del Foyer internacional des étudiants catholiques de la Ciudad Universitaria de París. Este curso ha sido 
recientemente publicado en Cursos Universitarios. Volumen IV. En tal curso, el carácter físico somático de las ideas de la teología y filosofía de los Padres Griegos se destacan como fundamentales para la teología y filosofía actual (Zubiri, 2014).

Zubiri durante esta etapa de su pensamiento veía una forma del cuerpo distinta desde cierta teología y filosofía griega, esto es, entender el cuerpo como "soma» decía en este Curso: "Las cosas que tienen materia son unas, como todo ente, por su principio formal, pero aquí se introduce una nueva dimensión. En estos seres la forma está recibida en un sujeto caracterizado por una interna exterioridad; la alteridad es aquí exterioridad; la distinción, distancia. En consecuencia, la forma se extiende en el tiempo y en el espacio. Aquí, tiempo y espacio no son entidades geométricas, sino algo que afecta a la acción formal del ser haciendo de ella, no simplemente una tensión, sino una ex-tensión y una dis-tensión en sentido activo: la espaciosidad y la temporeidad, desde las que se recoge y se repliega el ser en interna unidad. Tiempo y espacio son así el ámbito en que están circunscritas las posibilidades de la acción en que el ser consiste. Por esto hay muchos modos distintos de estar en el tiempo y en el espacio. No insisto más aquí. Estas cosas materiales son de tres órdenes (...) En primer lugar, los cuerpos (soma). Soma no significa en primera línea la simple materia pasiva e inerte, sino la manera cómo la unidad formal del ser tiene realidad en los límites circunscriptos y definitivos que le impone su «extensión». Lo que Ilamamos materia es el ente somático. En rigor hay que entender la materia desde el soma, y no el soma desde la materia" (Zubiri, 2004, p. 498).

Este texto está en la línea más propia que luego el teólogo francés M.-E. Boisrmard desarrollará y que será muy importante en el pensamiento zubiriano de los 70, porque "la concepción de "carne» semita tiene esa idea de la sárx griega; incluso se utiliza tal palabra griega en el prólogo de San Juan. Y esta carne implica a la vez cuerpo y alma, un todo, el hombre sin más" (Ascorra y Espinoza, 2011, p. 1065). Boismard lo indica muy claramente de la siguiente manera: " $Y$ el Verbo se hizo carne. Hemos visto más arriba lo que había que entender por este término 'carne'. No es solamente el cuerpo del hombre, independiente del alma. Según una manera de hablar en los libros sagrados, la carne designa al hombre entero, cuerpo y alma, pero considerado en su debilidad inherente al hecho de estar destinado a la corrupción" (Boismard, 1967, p. 81). Este concepto de cuerpo que Zu- biri comienza a trabajar tempranamente en su obra lo retomará con todo al final de su vida, a través del desarrollo de su etapa noológica.

Zubiri consideraba a través de su pensamiento una forma del cuerpo distinta, desde cierta teología y filosofía griega, esto es, entender el cuerpo como "soma», como presencia real decía entonces (más adelante será más claro y será el principio de actualidad mismo de la naturaleza, de la materia), terminología cercana a la de Heidegger de esos años. El filósofo español estaba muy influenciado por Heidegger, como es sabido, en estos tiempos (Espinoza, 2004a; Espinoza, 2006a; Espinoza, Ascorra y Vargas 2013; Espinoza, Vargas y Ascorra, 2012; Nicolás y Espinoza, 2008), esto le permite entre otras cosas, por una parte, tomar distancia de la fenomenología de Husserl, el primer trabajo de Zubiri fue completamente fenomenológico ${ }^{1}$ (Barroso, 2013) además de sumergirse en el horizonte ontológico propuesto por Heidegger en Sein und Zeit (1927) y, por otra parte, siguiendo al filósofo alemán, continuar con los filósofos griegos, en general, y Aristóteles, en especial, para repensar desde el origen «lo actual» (Heidegger, 1996), desde el clásico método de Heidegger de la Wiederholung (Heidegger, 2006; Espinoza, 2005).

De allí que en la década del 30, en torno al cuerpo de Cristo, Zubiri se permitía decir enfáticamente lo siguiente: "En el cuerpo glorioso de Cristo está la raíz de una glorificación que será comunicada al hombre y a la creación natural entera. Quizá sirva para este problema la distinción entre sôma y sárx [...] El sôma expresa la presencia real y circunscriptiva de un ser distenso en el espacio. Lo que llamamos materia es el ente que tiene este modo de ser somático. En el hombre esta materia es sárx, carne" (Zubiri, 2004, pp. 516-517).

Para poder decir esto a nivel técnico en teología griega, pero con vistas a la teología en general y actual, Zubiri ya estaba generando una concepción del hombre y en ello del cuerpo a la luz de una filosofía de la presencia con ciertos tintes de la ontología heideggeriana, pero con algo nuevo. Esto nuevo es un cierto carácter físico de esa presencia, de ese hombre y ese cuerpo que acontece en el mundo. Y eso será, luego el «momento de realidad» (en su etapa metafísica) y "formalidad de realidad» (en su etapa noológica). Es decir, tal momento Zubiri, lo estudiará, tematizará y precisará a lo largo de su vida. Y esto lo llevará a salir tanto de su pasado fenomenológico-ontológico (Husserl-Heidegger), para transitar por el camino metafísico y finalmente al noológico (Ferraz, 1994). 
Es interesante que se conserven testimonios de $\mathrm{Zu}$ biri, respecto a esta primera etapa, específicamente a esta imbricación de hombre con presencia («soma»). Así nos recuerda Laín Entralgo: "La idea de llamar 'soma' a la plena actualidad física del cuerpo humano vino a la mente de Zubiri, por lo que de él oí más de una vez, considerando el sentido de esa palabra griega en un texto de San Ignacio de Antioquía. Para un griego cualquiera, el sentido normal y fuerte del término soma era ni más ni menos el que para nosotros posee el término cuerpo; pero el autor cristiano quiere utilizarlo para llamar: soma tes alétheias 'cuerpo de la verdad', al conjunto sistemático de las verdades que constituyen el todo de la fe cristiana, esto es, al sistema de las varias proposiciones verbales en que el todo de esa fe se manifiesta a quien ha de profesarla. Así entendida, la palabra soma no es simplemente la traducción griega del 'cuerpo' de la lengua española, el body de la inglesa y el Leib de la alemana; para el cristiano 'cuerpo' como oposición al 'alma'. He podido ver que, en un sentido no religioso, sino estrictamente profano, Aristóteles llama soma tes pisteos, «cuerpo de la confianza» o "de la creencia» (Retórica, 1354 a 16), al conjunto de las pruebas que hacen convincentes una demostración. Soma en definitiva, es ahora el conjunto unitario de las notas en que se hace manifiesta y presente la esencia de algo" (Laín Entralgo, 1991, p. 232). Zubiri le entrega la autoría a la afirma-

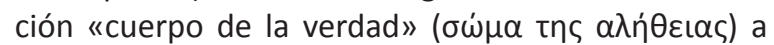
San Ireneo (Zubiri, 1993, p. 267).

Consideramos que este testimonio de Laín Entralgo es realmente muy importante porque nos sirve para dar mejor sentido al vocablo utilizado por el propio Zubiri en los años 30, pero diferimos tanto en la traducción como interpretación que se realiza ya de los griegos como del propio Zubiri. Porque respecto de los griegos ya sabemos por Heidegger de Ser y tiempo y en los textos de los años 30 como "De la esencia de la verdad" (1930) y "La doctrina de Platón de la verdad" (1932), por el mismo Zubiri en $\mathrm{Na}$ turaleza, historia y Dios (1944) e Inteligencia y realidad (1980), y antes por Reinhardt en Parménides (1916), en las obras de Otto a Dionisio: mito y culto (1933), Las musas: el origen divino del canto y del mito (1954) y Teofanía: el espíritu de la antigua religión griega (1956), también Hegel en las Lecciones de la historia de la filosofía (1837-1840) y Nietzsche en El nacimiento de la tragedia (1872), que alétheia no mienta verdad, sino desvelamiento, desocultamiento -Unverborgenheit-, si queremos la patencia por excelencia de la manifestación. Por eso soma tes aletheias mienta radicalmente, la actualización por antonomasia de la materia, esto es, el hombre en tanto cuerpo. El texto es casi reduplicativo, esto es, presencia de la presencia, actualización de lo que se hace presente, de lo que está presente. Y en lo referente a la cita de Zubiri, es obvio que él busca ese sentido para «soma» y en especial para el cuerpo glorioso de Cristo.

En todo caso, Zubiri con esta categoría de "soma» pensaba, a una, al hombre y su cuerpo como una unidad de presencia en la totalidad (Zubiri, 2006a; Zubiri, 2006b). Y aquí está la base para entender su trabajo posterior en torno a la "persona encarnada» desde su filosofía última, esto es, de la realidad o, mejor dicho, de la «formalidad de realidad».

\section{2}

Vayamos por partes. ¿Qué es la realidad? Por medio de ciertas determinaciones del pensamiento de Zubiri desde los años 70 en adelante (desde su breve pero intenso curso acerca del tiempo), "Dos lecciones acerca del tiempo" en 1970. Estas lecciones se encuentran en Espacio. Tiempo. Materia (1996). Este curso es un estudio complejo del tiempo en todos sus momentos que lo constituyen, sin embargo, hablando con rigor, no es un libro propiamente dicho. Pues no alcanzó a ser estructurado como tal. Fueron distintas lecciones que se hicieron sobre el tiempo en 1970. De las cuales Zubiri luego trabajó para un futuro libro, la primera de las lecciones versaba sobre el tiempo como línea (el concepto descriptivo del tiempo) y fue la que aparece ampliada y actualizada en la revista Realitas /I en 1976; las otras lecciones (el tiempo estructural y el tiempo modal) no fueron trabajadas como debían haber sido (Espinoza, 2006a). Y elevadas desde el horizonte noológico que se despliega en la trilogía Inteligencia sentiente (1980-1983) y algunos otros textos de este período, podemos dar de manera muy definitiva una cierta comprensión de lo que es la realidad para el pensador español y también entender de forma más acabada la articulación de la realidad con el ser (Espinoza, 2004b; Espinoza, 2005); en cierta forma, por fin, acabar la disputa con Heidegger y en especial los heideggerianos respecto al papel del célebre Ser y tiempo de 1927 en la historia del pensamiento del siglo XX (y en la obra del filósofo español); y en este final, Zubiri incorpora realmente a Heidegger dentro de su filosofía -el filósofo de la Selva Negra ya no es problema para Zubiri, como sí lo era en Sobre la esencia, al contrario, lo incorpora dentro de los más propio de su última filosofía (Espinoza, 2014; González, 2004). 
Entonces, ¿qué es la realidad?: “... la verdad es que estamos instalados modestamente, pero irrefragablemente, en la realidad" (Zubiri, 1980, p. 15). Pero, solamente lo estamos de modo sentiente. La aprehensión propia del hombre es una aprehensión de tipo impresiva, pero lo que se siente en esa impresión es la realidad misma de los contenidos. Se sienten los contenidos de un modo determinado, se sienten como "de suyo" lo que son en la aprehensión. Independiente del acto de aprehensión sentiente, se siente en ese mismo acto de aprehensión sentiente, se siente en ese mismo acto algo que es formalmente anterior - «prius»- a él, el mero carácter de realidad del contenido, esto es, se siente al contenido en la formalidad de realidad (Espinoza, 2014). "Realidad es el modo de ser "en propio», dentro de la aprehensión misma. «En propio» significa que pertenece a lo aprehendido, por tanto, aún antes de la aprehensión misma (prius)" (Zubiri, 1982, pp. 12-13). Para entender mejor este elemento noológico: "No se trata de ir tras lo físico mismo, o sea, tras el emerger mismo de lo real qua real que se nos impone inexorablemente; esto es un modo muy adecuado para comprender acabadamente lo que luego la filosofía francesa, italiana o alemana ha llamado simplemente Acontecimiento (Événement, Evento. Ereignis respectivamente). Porque tras este emerger físico no se esconde nada y esto es fundamental no olvidarlo (la misma aprehensión primordial debe ser vista de esta forma)". (Espinoza, 2014, p. 151; Ferraz, 1994; Gracia, 1986; Pintor Ramos, 1994b). Como dice Diego Gracia de forma muy clara en el "Prólogo" de Realidad y tiempo en Zubiri: "Lo aprehendido se me actualiza como «de suyo». El «de suyo» no es el "en sí» del realismo ingenuo, ni el «en mí» del idealismo, también ingenuo. El «de suyo» es realidad, pero realidad en la aprehensión, no allende ella. A pesar de lo cual, en el "de suyo» hay un momento que Zubiri llama de "prius». Se ha discutido mucho lo que puede significar ese término. Espinoza Lolas da una explicación que a mí me parece definitiva. En la aprehensión la iniciativa no la toma la conciencia, como sucedía en Husserl, sino que es la propia realidad, el propio "de suyo» el que sale por sus fueros y se impone. Lo originario no es ningún tipo de "posición», como sucedía en el idealismo, sino la «imposición» de la propia realidad. Eso es lo que Zubiri llama "fuerza de imposición»" (Gracia, 2006, p. XIX).

Esto permite que la «actualidad» de lo real se sienta como «de suyo» (Espinoza, 2014; Ferraz, 1994; Gracia, 1986): “... lo sentido se me presenta como algo que tiene una especie de fuero interno propio: es caliente, es frío, es pesado, etc., de suyo. No se trata de que el contenido sea propio de un sujeto que esté por debajo o por detrás de lo propiamente sentido, sino que de suyo significa que eso que es el contenido de la impresión tiene ese carácter formal propio. Pues bien, este carácter de suyo es lo que llamo realidad. Cada cosa es real precisa y formalmente por ser de suyo aquello que ella es en impresión. Ser real significa pura y simplemente ser de por sí, ser de suyo aquello que nos presenta en la impresión. El de suyo, pues, lo que constituye la realidad en cuanto tal". (Zubiri, 2008b, p. 153). Heidegger piensa algo similar a comienzos de los años 30, en pleno "giro» de su pensamiento. Hay un texto muy importante en esta misma línea donde Heidegger explica las «anticipaciones de la percepción» (A 143, B 182) en el Capítulo I (EI esquematismo de los conceptos puros del entendimiento) del Libro Segundo (Analítica de los principios) de la Analítica Trascendental de la Crítica de la razón pura de Kant; en este texto Heidegger hace la interpretación fenomenológica de la importancia radical de que Kant anticipe lo real en la percepción misma como condición de posibilidad de la objetividad del objeto (Heidegger, 1975). "Realidad es el carácter formal -la formalidad- según el cual lo aprehendido es [...] algo "de suyo»" (Zubiri, 1980, p. 10). El término de "formalidad de realidad" a diferencia del antiguo término de realidad en su etapa metafísica puede llevar a equívocos. Zubiri es claro: "No se trata de un concepto metafísico como en la Edad Media, sino de algo absolutamente distinto, de un momento sentiente de carácter descriptivo" (Zubiri, 1980, p. 35).

Para el filósofo español la realidad no es algo de tipo conceptual, sea esto lo que fuere; incluso duda que pueda haber alguna lengua en especial que pueda expresar algo así como un concepto absolutamente universal que dé cuenta de la realidad: "No se trata, repito una vez más, del concepto de máxima universalidad. Cuál sea este concepto es algo sumamente problemático y que depende inclusive de las lenguas que se empleen. Y es, además, verdaderamente problemático que exista un concepto de total universalidad" (Zubiri, 1980, p. 123). En esta postura Zubiri se coloca en el antípoda de toda una tradición filosófica que ha perforado la filosofía occidental por siglos con el tema de entender lo más radical de la realidad por medio del rasgo conceptual de la universalidad. Para él la realidad es todo lo contrario a un concepto, la formalidad está sentida en el acto mismo de aprehensión impresiva de las cosas, esto es, en el sentir humano (Gracia, 1986); y esto es fundamental para entender al hombre en su carácter personal (López Quintas, 1985) y en su cuerpo (Conill, 1991). 
La realidad como formalidad mienta, entonces, el "de suyo» que primariamente acontece en la aprehensión; se impone en ella y en esta imposición se siente, a la una, su carácter de ser, que indica ese rasgo de estar siendo en la aprehensión y, en ello, el mundo. Realidad y ser van de la mano en Zubiri y no podría ser de otra manera, pues el diálogo con Heidegger sigue hasta el final de su vida (Espinoza, 2014; González, 2004).

La articulación realidad y ser es constructa; y mienta tanto una diferencia asimétrica de sus momentos como una unidad entre ambos términos. Toda cosa se notifica a sí misma en cuanto esa unidad física constructa en actualidad del «de» que la constituye como un todo sustantivo de «notas». Zubiri dice que: “... es la unidad estructural que consiste en ser un sistema "constructo", esto es, un sistema en que cada una de sus notas no tiene realidad propia de nota más que siendo intrínseca y formalmente "de» las demás" (Zubiri, 1983, p. 113). Para Zubiri, "Las cosas están constituidas por «notas» [...] toda nota lo es por estar articulada con las demás [...] El «de» le pertenece intrínsecamente [...] Es lo que inspirándome en las leguas semitas llamo carácter o estado "constructo» de toda nota" (Zubiri, 1986, pp. 43-44). Y visto desde un modo más radical de las cosas mismas, Zubiri piensa que el carácter constructo, su unidad: “... es la unidad estructural que consiste en ser un sistema "constructo", esto es, un sistema en que cada una de sus notas no tiene realidad propia de nota más que siendo intrínseca y formalmente «de» las demás. El ser sistema constructo es la esencia misma de lo real en cuanto real. De ahí su función radical" (Zubiri, 1983, p. 113). Por este motivo, Inteligencia y razón (1983), que es el último libro de la Trilogía (y escrito por Zubiri, murió el mismo año de su presentación), es el libro que mienta lo metafísico de antaño (Sobre la esencia, de 1962) a la altura de una mirada noológica.

Sin embargo, esta unidad de diferencia está centrada, por ser constructa desde uno de los términos de la articulación (por eso es asimétrica), esto es, la realidad, el constructo no es una igualdad, sino que es en dominancia de un término acerca del otro. Nosotros hemos dicho, en otros artículos, (Espinoza, 2006b) debemos estar atentos a la lectura que debemos realizar de estos momentos, de modo particular del logos y la razón (también es constructo), esto porque desde un análisis descriptivo genético los tres momentos pueden aparecer desarticulados, uno antes que el otro, donde el «logos» aparece como aquel que da las bases para que luego la razón se despliegue (Gracia,
1986). Por este motivo, no debemos olvidar que el pensamiento de la obra madura de Zubiri es constructo: “...un análisis descriptivo constructo nos mostraría que la razón misma que busca indagar lo que se siente en aprehensión primordial nos exige el logos para que le dé sus materiales de apoyo. Dicho en términos vulgares, para pensar se necesita un lenguaje, pero esto no quiere decir que el lenguaje sea anterior al pensar y que de aquél nazca éste. Sin embargo, tampoco quiere decir que porque pienso hablo y que, por tanto, el pensar sea anterior al lenguaje. Lo que tenemos es una unidad constructa entre pensar y hablar, unidad que no se puede analizar desarticulándola. El hombre está físicamente sumergido en la realidad sentida en esa unidad de "hablar-pensar». Por eso es muy interesante que Zubiri llame sin más a estos dos momentos ulteriores de la intelección sentiente simplemente "razón» o si se quiere 'razón sentiente'" (Espinoza, 2004b, pp. 33-34).

Es la realidad de lo real la que da de sí su ser, así es como finalmente Zubiri asume a Heidegger de Ser y tiempo dentro de su obra; tal como el propio Heidegger lo hacía al interior de su pensamiento después de los años 30 con la profundización de la filosofía que funda el tema del ser, esto es, el pensamiento del Ereignis (Espinoza, 2014; González, 2004). Y esto es lo que tenemos que señalar para poder acceder al tema de la persona humana de manera correcta y en toda su magnitud, sin caer en reducciones simplonas. El ser, en sentido estricto, no es otra cosa (dicho de modo ontológico) que la manera en que la realidad "está siendo» actual en el mundo, su «luz»; y el tiempo es la modalización de esa luz, esto es, su, por decirlo en metáfora, su «color»: "No solamente la realidad se aprehende en aprehensión primordial como "de suyo", entendido como un "de suyo que es», un "de suyo que está siendo tempóreamente», sino que la misma aprehensión primordial queda, como es obvio, "tocada» por ese carácter tempóreo [... ] la intelección misma se desplegaría en sus momentos ulteriores de logos y razón por motivos dinámicos no solamente derivados del carácter impresivo de la aprehensión primordial sino también por motivos tempóreos" (Espinoza, 2006, p. 350).

Es el instante en que está esa luz de la realidad siendo en el mundo; es cómo está siendo esa luz en el mundo, está siendo en el instante de la "coloratura» de la realidad. Es el matiz impresivo mismo en la que la realidad siendo en el mundo «es». Ese carácter impresivo tempóreo de lo real aprehendido en aprehensión primordial va a ser una de las fuentes del desa- 
rrollo ulterior de la inteligencia como logos y razón. El carácter tempóreo sentido en aprehensión primordial da el carácter modal mismo del ser sentido cómo el «color» de la realidad, los "tonos» de la luz del ser -no olvidemos que el ser es la «luz» de la realidad y ésta es la «luminaria» misma- (Espinoza, 2014). Ese "color» sentido en la luz que está siendo la realidad nos permite distender y desplegar lo sentido porque el tiempo en su presentarse a la luz de su ser queda presente, en esa misma luz, como "color» de la realidad; "color» que hace visible el presente mismo que se despliega de la cosa sentida; el "color», esto es, el tiempo lanza al hombre (Espinoza y Orellana, 2009) a hacerse cargo de lo real sentido (es cosa de pensar, por ejemplo, en todo lo que ha sido el sol para el hombre, pero nos referimos no a un sol en el sentido de una construcción cultural, sino, anterior a eso, a un sol sentido en aprehensión primordial de real, un sol "de suyo que es» y, además, se siente de modo tempóreo). El «color» del ser, su tiempo, dará una buena idea para ver cómo la inteligencia se hace cargo de eso real sentido tempóreo y en ello mismo, dicho "color», dicho "presente en tiempo» requiere a la inteligencia a ir creando formas de dominio de ese presente, en efecto, ejemplo los rasgos del tiempo modal desde los que es posible ver con claridad la imbricación de este con el ser y la realidad (Espinoza, Ascorra y Vargas, 2013; González, 2004), por ejemplo, la propia mano se vuelve intelectiva a luz de lo sentido como real y ella se vuelve configuradora de lo real en el pasar de su día y configuradora de las cosas en el sentido más simple del vocablo (Pintor Ramos, 1993).

Realidad y ser no siendo lo mismo se articulan de un modo muy especial: "Realidad y ser no son lo mismo. Decimos, por ejemplo, que una realidad cualquiera, la plata, tiene determinados caracteres...Pero no es que la plata los tenga, sino que constituyen la realidad argéntea en sí misma. En definitiva, lo que entendemos por realidad a propósito de cualquier cosa es aquello que a una cosa le compete de suyo, y no simplemente aquello que le sobrevenga a una realidad determinada por su relación con otras" (Zubiri, 2008b, p. 290). Esta determinación de la realidad como los caracteres que le competen «de suyo» a la cosa real está pensada a partir de una visión metafísica de la realidad. Tal visión fue defendida por Zubiri hasta el final de sus días, pero lo fue desde una matización noológica (Pintor Ramos, 1994b). La realidad es el «de suyo» (desde sí misma), es esto y no otra cosa; pero tal afirmación debe ser entendida desde la aprehensión misma en su acto de aprehender (y no salirnos de ella; este tipo de análisis tan cercano a la fenomenología de Husserl y Heidegger fue parte fundamental del pensar zubiriano). Realidad es una formalidad (esto es, un modo de quedar las cosas reales en tanto que aprehendidas) en donde las cosas reales quedan en la aprehensión como siendo meramente "de suyo»; esto es, quedan en la aprehensión humana como siendo propias de sí mismas («en propio»), anterior («prius») a la misma aprehensión pero «en» ella misma. Y esto es fundamental para entender de modo adecuado el pensamiento del autor español. En esta anterioridad creemos ver uno de los aciertos más importantes de Zubiri para la filosofía actual; es una posibilidad para entender, lo que se ha llamado, el acontecimiento en español y con los matices de: Événemennt en francés (Badiou, 1999; Badiou, 2005) o Ereignis en alemán (Heidegger, 2003).

Lo ideal es dejar claro un breve matiz y sutileza del lenguaje que indica tres dimensiones distintas de la realidad, pero que se puede llevar a confusión si no lo sabemos y que son matices que en español son claves para entender lo que Zubiri entiende por realidad personal; término que estará asociado al de cuerpo. Esa confusión está en creer que tanto en alemán como en francés se dice lo mismo que en español (y dejemos claro que tampoco se da semejante igualdad en francés como alemán). Événemennt mienta una cierta irrupción de un evento o suceso que rompe el tejido psíquico, social e histórico de la realidad humana; es la irrupción que no se deja atrapar por racionalidad alguna y que al contrario genera incoadamente una nueva racionalidad (esto no lo podemos olvidar para pensadores desde Foucault a Badiou). En cambio, Ereignis indica no un suceso o evento, esto sería algo fundamental pero empírico y óntico en el trato del ser con el hombre, lo que se indica aquí es una "apropiamiento" del hombre en el mundo, del hombre en el ser, de un pueblo en su todo, un modo realmente propio que no se deja homogeneizar, ni calcular, ni determinar mecánicamente por ninguna ideología ni sistema de pensamiento (esto se puede apreciar desde pensadores como Heidegger a Sloterdijk). Y, finalmente, Acontecimiento señala rotundamente otra cosa, un matiz muy distinto a los anteriores. La palabra viene de contingere y allí lo que suena es el cum y tangere. $\mathrm{Y}$ aquí se indica la acción misma de tocar. EI Acontecimiento mienta la dimensión física de estar tocado radicalmente en y por la realidad, y en este estar tocado, en este contacto, se da el hombre en sentido pleno. Es la «tocadura» que constituye a todo y en especial al hombre mismo desde su propia aprehensión sentiente, en la integridad misma de su cuerpo; en su ser «aquí» (Espinoza, Ascorra y Vargas, 2013). La rea- 
lidad "toca» y en ello constituye lo real. Y en este ser tocado, el hombre, en tanto que cuerpo, es arrastrado por lo real mismo cuando lo siente (aquí está todos los pensadores latinos desde Ortega, Zubiri a Duque).

Por esto, la realidad en este carácter de «acontecimiento", del quedar de las cosas en tanto reales, esto es, siendo absolutamente "suyas» en la aprehensión y en anterioridad, quedamos sumergidos "físicamente» en estas mismas cosas, pues nos sentimos arrastrados por un fuerza tal que nos toca y constituye; y que no podemos asir nunca del todo. "Para él [Zubiri] la realidad es todo lo contrario a un concepto, la formalidad está sentida en el acto mismo de aprehensión imprensiva de las cosas, esto es, en el sentir mismo humano. De allí que diga, para diferenciarse absolutamente de la filosofía europea, que la formalidad es algo, en cierto modo, "físico». ¿Qué quiere decir el vocablo "físico» para el pensamiento de nuestro filósofo? Es un vocablo que debe ser entendido de un modo originario, al modo como lo entendieron los mismos griegos. Real y físico mientan lo mismo en la filosofía zubiriana" (Espinoza, 2006, p. 3) la cual es parte de la clásica "Nota General" en Sobre la esencia y el comienzo de Inteligencia y realidad (Marquínez, 2006).

Con este matiz de entender la realidad como formalidad, Zubiri ve que se supera el realismo en todas sus formas como el idealismo también en todas sus variantes. Por esto puede decir: "Realidad es el modo de ser "en propio», dentro de la aprehensión misma. «En propio» significa que pertenece a lo aprehendido, por tanto, aún antes de la aprehensión misma (prius). Como este modo de quedar en la aprehensión es un modo de quedar en impresión, resulta que la aprehensión es un acto de impresión de realidad. En ella su contenido es actual en la impresión, pero sin referencia ninguna a una respuesta. Es lo que llamo mera actualidad: lo aprehendido está presente y solamente está presente. Pues bien estos tres momentos (impresión, en propio, y mera actualidad) constituyen unitariamente lo que llamo ser de suyo. He aquí la formalidad de realidad: un modo de alteridad que consiste en el "de suyo»" (Zubiri, 1982, p. 13). En efecto, las cosas se nos imponen en la aprehensión rotundamente, nos arrastran y arrebatan inexorablemente; se nos imponen en el cuerpo que somos, esto es, un cuerpo sentiente intelectivo: presión, contacto, audición, olfato, sensibilidad laberíntica, kinestesia, cenestesia, vista, etc., (Zubiri, 1980). En tal imposición, las cosas se nos manifiestan "físicamente» con sus propios caracteres, nos tocan; esto es, las cosas son en sí mis- mas estos caracteres que las constituyen y que se nos imponen en la aprehensión corporal en su conjunto. No hay nada por detrás o debajo de la cosa que sea base o sustento esencial de esta misma cosa (la realidad nunca es sustancial, ya al modo realista como $a$ posteriori, ya al idealista como a priori), sino simplemente es la cosa misma la que es un todo coherente y sistemático de notas; y son estas notas las que son "de suyo" en la aprehensión. Por tanto, tenemos una primera determinación fundamental de la realidad de lo real aprehendido, ser meramente "de suyo" (término muy español que Zubiri desde la década de los 30 ya lo usaba con valor filosófico para traducir ni más ni menos que el arche de Anaximandro).

\section{3}

Ahora bien, la realidad humana es una realidad muy especial, es una realidad «real», esto es, una realidad de suyo "suya», reduplicativamente real o, si se quiere, reduplicativamente "suya». ¿Qué mienta ese carácter reduplicativo real? ¿Qué mienta ese carácter tan propio de este tipo de realidad humana? El carácter físico de "de suyo" indica que somos una realidad con suficiencia para ser en un sistema de notas o momentos coherentes entre sí; y en tal sistematicidad y coherencia se expresa la realidad ella misma en el mundo, se impone en él con todos sus matices. Pero nosotros como humanos añadimos una tipificación esencial y cualitativamente distinta a todas las otras realidades que acontecen en el mundo. Es ese carácter de "suyo» del "de suyo», su reduplicación. Una realidad "suya», eso es lo que somos, o, si se quiere, una realidad «de suyo suya». Esto no quiere decir una mera tautología vacía o un juego de palabras. Lo que se indica acá es que la realidad humana es formalmente «suya». ¿Qué señala ese carácter formalmente "suyo» de la realidad humana? Aquí se juega lo propiamente humano.

El de "suyo» formal y físicamente indica que la realidad humana está abierta primera e inexorablemente a "sí misma» y por ello luego (en un sentido ontológico y no cronológico) al mundo. Ese carácter físico formal de la apertura a su "sí mismo» de toda realidad humana es una tremenda innovación de todas las realidades en sus formas y modos de ser real a nivel cósmico evolutivo. La realidad humana es «suidad» (Gracia, 1986; Pintor Ramos, 1994a), o, como se dijo, realidad «de suyo suya». Esa "suidad» mienta lo que desde antiguo se conoce (pero sin la precisión conceptual que se requería) como la «propia espiritualización del hombre» en contraste a la mera activación 
movente del animal. La propia apertura de la realidad a su carácter real, a su "sí mismo», implica entre otras cosas su esencial libertad y es una apertura física a ese "sí mismo», o sea, está arrastrado, tocado a su «sí mismo». Y por ello somos la única realidad libre. Al estar abierto a "sí mismo» se es formal y físicamente libre; libre porque no se está determinado necesariamente por el carácter cósmico de su realidad, sino que está perforado esencial, formal y físicamente de su mismidad abierta. El hombre es realidad física abierta al mundo, pero está en el cosmos junto a otras formas y modos de realidad. $Y$ es ese carácter de libertad es la que se expresa en la inteligencia sentiente, en la voluntad tendente y el sentimiento afectante. Toda la intelección humana reposa en el carácter "suyo», esto es, a la apertura a "sí mismo» de la realidad humana en toda su corporalidad. Y por esto la intelección recubre a todo el hombre en su conjunto y lo recubre volviendo al hombre formalmente en una realidad en el mundo, mundo real, esto es, mundo en sí mismo abierto (luminoso) y en esa apertura se co-determina con otras realidades, pero es una co-determinación de tipo cósmica.

Este carácter de "suidad" de la realidad humana lo vuelve de inmediato "absuelto» de todas las otras realidades no "suyas», no abiertas (o libres, dicho más simplemente) que están en co-determinación cósmica. Y no meramente «absuelto» respecto de cualquier realidad no humana, sino de las otras realidades humanas e incluso de "sí mismo". La realidad humana es la única realidad absuelta mundanalmente aunque esté siendo parte del "aquí» somático cósmico por su cuerpo (Espinoza, Ascorra y Vargas, 2013), pero como hemos dicho su cuerpo es cuerpo libre, cuerpo abierto, su "aquí» es un "aquí» en libertad y por ende del tipo trascendental. El hombre es un cuerpo en libertad (por ser abierto) y por esta razón es un cuerpo trascendental (y de allí todas las formas de comunidades y organizaciones que va desarrollando el hombre a lo largo de su vida e historia son del tipo de cuerpos, cuerpos en libertad, esto es, transcendentales: la familia, la amistad cívica, el parlamento, una empresa, una cofradía, etc.). Este cuerpo libre es, noológicamente, un «aquí» inespecífico o, dicho, de modo metafórico, es un "trozo» de cosmos, pero mundanal. $Y$ por este motivo el hombre como realidad corporal mundanal está "ab-suelta» en sentido estricto y etimológico. Y ese carácter físico de «ab-suelto» indica lo que ya hemos dicho pero con un matiz fundamental, es decir, incondicional. "Es que el hombre no sólo tiene realidad, sino que es una realidad formalmente «suya», en tanto que realidad. Su carácter de realidad es «suidad». Es lo que, a mi modo de ver, constituye la razón formal de persona. El hombre no sólo es real, sino que es «su» realidad. Por tanto, es real «frente a» toda otra realidad que no sea la suya. En este sentido, cada persona, por así decirlo, está «suelta» de toda otra realidad: es «ab-soluta» [...] Pero sólo relativamente absoluta, porque este carácter de absoluto es un carácter cobrado'” (Zubiri, 1984, p. 373).

La realidad humana no está condicionada por nada, por eso su libertad. Ya para ser un mártir, ya para amar, ya para lo que sea (incluso un criminal). Todo acto humano y práctica humana es libre pues está formalmente "absuelta» (obviamente no estamos hablando de rasgos estimúlicos tipos de lo fisiológico humano). Y de aquí nacen las dimensiones estética, ética, política, teologal del hombre. La realidad humana no está condicionada meramente a ser un sistema sustantivo de notas coherentes que están siendo en el "aquí» cósmico, sino que es una realidad absuelta (libre) en el mundo; libre para realizar su propia vida puesto que "de suyo» el hombre se tiene físicamente a "sí mismo» (por eso dicho con otros términos es consciente, reflexiona y por eso se dice desde hace siglos que el hombre es «espiritual»). Los alemanes hablan de lo unbedingt que se traduce por incondicionado, sin embargo, lo que indica el término es el carácter no "cósico», no empírico del hombre (Zubiri diría que no es meramente "talitativo» o Heidegger habla de lo existencial para distinguirlo de lo óntico). EL filósofo Félix Duque respecto al concepto de lo incondicionado [unbedingt] cita a Schelling: "Llamamos bedingen (condicionar) al acto por el cual algo deviene Ding (cosa) [...] lo cual es tanto como decir que nada puede ser puesto por sí mismo como Ding ([cosa]) [...] Así que Unbendingt (incondicionado) es aquello que de ningún modo puede hacerse Ding (cosa)" (Duque, 1998, p. 258).

Lo «ab-suelto» indica el rasgo propio de la «suidad» humana en vistas a todas las otras realidades. Por esto que se dice que el hombre es «absoluto» (en alguna medida casi como Dios). Lo libre por excelencia, el «aquí» somático abierto al mundo, pero «ojo» siempre un «aquí» y por ende traspasado de lo empírico, cósico, talitativo, óntico para realizar su absolutez. El hombre como realidad absoluta lo es siempre de modo relativo; es un ser histórico. Su "aquí» corporal lo inserta en el movimiento (en el devenir) cósmico y en ello nace precisamente el carácter histórico tan propiamente humano; y así ese devenir se expresa, en definitiva, en las dimensiones estética, ética, política, teologal, etc. del hombre. 
La realidad humana es absoluta, pero relativa: "La persona, en efecto, tiene que ir haciéndose, esto es, realizándose en distintas formas o figuras de realidad. En cada acción que el hombre ejecuta se configura una forma de realidad. Realizarse es adoptar una figura de realidad [...] Y el hombre se realiza viviendo con las cosas, con los demás hombres y consigo mismo. En toda acción, el hombre está, pues, "con» todo aquello con que vive" (Zubiri, 1984, p. 373). Por esta razón, el hombre es un absoluto relativo. El carácter relativo no es nada negativo ni peyorativo, sino toda la riqueza misma del carácter absoluto de la realidad humana. El hombre como hemos dicho al comienzo de este artículo es una realidad "que es», que está siendo en el mundo. Y se es en el mundo desde un "aquí» cósmico. Este carácter cósmico mundanal del ser de la realidad humana confiere al hombre que sea lo que es como tal y así sea propiamente hombre. "El cuerpo es la actualidad misma del hombre, es su estar siendo en el cosmos con toda su materialidad individual, social e histórica. Es un cuerpo de suyo propio, entre otros cuerpos, ya del modo filético, ya del modo social y es, además, un cuerpo que se entrega de generación en generación como ciertas capacidades de actualidad, es decir, modos de ser físicamente en el cosmos y de estar abiertos al mundo, es la historia entendida de un modo corporal. Y allí, en definitiva, estaría el carácter teologal corporal que integra todas estas otras dimensiones humanas como un cierta religación en comunidad de unos con otros en vistas a algo que los supera y les da un sentido, un cierto camino por donde deben caminar en conjunto, con su propia individualidad, entre todos y en esas dotes actuales que se han entregado" (Espinoza, 2014, p. 11).

No podría ser hombre de otra manera, sería lo que fuera pero no realidad humana. El hombre como absoluto relativo es lo que mienta, radicalmente, el carácter de persona.

\section{CONCLUSIÓN}

Finalmente, si nos hemos dado cuenta, la vieja y moderna categoría de sujeto o simplemente de yo para comprender acabadamente al hombre es totalmente innecesaria (Gracia, 2009), pues ya no da de sí para expresar al hombre ya en su carácter real (físico) ya en su carácter "suyo». El yo es una pobre categoría que dio lo que tenía que dar en un horizonte de pensamiento europeo moderno, pero que ya no puede expresar el dinamismo real mismo en lo que consiste la realidad humana. Tal dinamismo mienta una realidad con otras realidades en libertad y sumergidos en el cuerpo mismo que les acontece. Y en tal sumergimiento está desplegándose a nivel psíquico, social e histórico la riqueza misma de esa absolutez, pero en relatividad.

La idea de Zubiri de realidad es una idea, en su nacimiento heredera de la fenomenología alemana de comienzos del siglo $\mathrm{XX}$, que permitió hacerse cargo de los múltiples fenómenos más radicales que urgen al hombre, entre estos fenómenos el del propio hombre ante sí mismo y ante el mero mundo. En ello Zubiri con su trabajo fino y preciso de matices nos da la posibilidad de entender al hombre, como lo hemos visto, desde una matriz conceptual rica y potente que nos permite dar de forma más adecuada con lo propiamente humano. Ese carácter físico del "de suyo" del carácter real, en general, y en lo específico humano es un matiz de su pensamiento que nos lanza por distintos lugares a repensar lo que se había dicho del hombre y de lo que puede un hombre. Gracias a esta concepción del hombre desde la realidad humana, de la persona y su cuerpo creemos que podemos repensar otras dimensiones fundamentales de éste, entre ellas la política.

De allí, a lo mejor, que la dimensión misma política también sea real, física y corporal, y desde este carácter esté dándose toda la historia de unos con otros, con todo el dolor que a veces esto conlleva junto a las esperanzas de que un día todos serán cada vez más libres, esto es, más «suyos». A lo mejor la dimensión política de la persona humana sea volver una y otra vez con el otro y por el otro para que sea más real, esto es, más "suyo»; más libre. Pero siempre una libertad que se va levantando desde el cuerpo de unos trabados con otros. Es posible que lo señalado sea lo que nos permite entender, en el mal llamado "mito de la caverna» de la República de Platón, por qué ese esclavo liberado y que ha salido de la caverna y que ya vive bajo la luz del sol tenga la necesidad que se le impone físicamente de volver a buscar a los otros que siguen en la oscuridad. Y además está tan arrastrado y poseído por esta luz que volverá una y otra vez hasta cuando todos ya se sientan liberados, bajo la luz del sol siendo un cuerpo social. Una verdadera Atenas.

\section{AGRADECIMIENTOS}

Este artículo es parte del Proyecto Fondecyt $\mathrm{N}^{\circ}$ : 1140973: "Realidad y técnica en Zubiri". 


\section{NOTAS}

1. El filósofo español estaba totalmente sumergido en el ámbito filosófico alemán que estaba instaurándose como un nuevo horizonte de pensamiento; comprendía muy bien la fenomenología inaugurada por Husserl y no podemos olvidar que sus dos primeros trabajos

\section{BIBLIOGRAFÍA}

Ascorra, P. y Espinoza, R. (2011). Cuerpo y alma en Zubiri... Un problema filosóficoteológico. Pensamiento, 67, 254, pp. 1061-1075.

Badiou, A. (1999). El ser y el acontecimiento. Buenos Aires: Manantial.

Badiou, A. (2005). Lógicas de los mundos. El ser y el acontecimiento, 2. Buenos Aires: Manantial.

Bañón, J. (1999). Metafísica y noología en Zubiri. Salamanca: Publicaciones. Universidad Pontificia de Salamanca.

Barroso, Ó. (2013). En qué sentido puede entenderse la filosofía de Zubiri como una fenomenología. Revista de Filosofía, 38, pp. 29-52

Boismard. M. É. (1967). El prólogo de San Juan. Madrid: Fax.

Cerezo, P. (1996). El hombre, animal de realidades. En: VV. AA. La filosofía de Zubiri en el contexto de la crisis europea. Santiago de Compostela: Universidad de Santiago de Compostela, pp. 53-71.

Conill, J. (1991). El enigma del animal fantástico. Madrid: Tecnos.

Corominas J. y Vicens, J. A. (2006). Xavier Zubiri. La soledad sonora. Madrid: Taurus.

Duque, F. (1998). Historia de la Filosofía Moderna. Madrid: Akal.

Espinoza, R. (2004a). ¿Por qué, Herr Kollege, no ha hablado usted antes? La crítica de Zubiri a Sein und Zeit. Cuadernos Salmantinos de Filosofía, XXXI, pp. 201-249.

Espinoza, R. (2004b). Realidad y Logos. ¿Es Zubiri un pensador posmoderno? Philosophica, 27, pp. 109-157. propiamente filosóficos de alto nivel están incardinados en la fenomenología. Para aprobar en 1921 la Licenciatura en Filosofía Superior en la Universidad Católica de Lovaina presentó la tesina: Le problème de l'objetive d'aprè Ed. Husserl: La Logique pure. Luego se doctoró ese mis- mo año en Madrid con la tesis: Ensayo de una teoría fenomenológica del juicio. Esta tesis fue publicada en 1923 y es el primer libro sobre fenomenología de Husserl fuera de Alemania. Ambos textos se pueden encontrar en el volumen Primeros escritos (1921-1926).
Espinoza, R. (2005). En torno al problema del Ereignis... Das Ereignis ereignet das Sein. Philosophica, 28, pp. 61-92.

Espinoza, R. (2006a). Realidad y tiempo en Zubiri. Granada: Comares.

Espinoza, R. (2006b). Zubiri y Husserl. Una crítica desde el carácter físico a la intencionalidad. Cuadernos Salmantinos de Filosofía, XXXIII, pp. 341-367.

Espinoza, R. (2014). Realidad y ser en Zubiri. Granada: Comares.

Espinoza, R. y Ascorra, P. (2012). Heidegger y Zubiri...y «el problema de Dios». Veritas, 27, pp. 9-33. http://dx.doi.org/10.4067/ S0718-92732012000200001

Espinoza, R., Ascorra, P. y Vargas, E. (2013). Realidad y actualidad. Una primera aproximación al tema del cuerpo. Arbor, 189, 760, a017. http://dx.doi. org/10.3989/arbor.2013.760n2003

Espinoza, R y Orellana, O. (2009). Tiempo y cosa: La influencia de Einstein en el pensamiento de Zubiri en torno al tiempo lineal. Pensamiento, 65, 246., pp. 809-832.

Espinoza, E., Vargas, E. y Ascorra, P. (2012). Nietzsche y la concepción de Naturaleza como Cuerpo. ALPHA, 34, pp. 95116. http://dx.doi.org/10.4067/S071822012012000100007

Ferraz, A. (1994). Zubiri, el realismo radical. Madrid: Pedagógicas.

González, A. (2004). Ereignis y actualidad. En: Gracia, D. Desde Zubiri. Granada: Comares, pp. 103-192.

González, A. (2010). La reflexión de Zubiri sobre la técnica. Rocinante, 5, pp. 33-62.

Gracia, D. (1986). Voluntad de verdad. Para leer a Zubiri. Barcelona: Labor.
Gracia, D. (2003). La antropología de Zubiri. Anthropos, 201, pp. 64-80.

Gracia, D. (2006). Prólogo. En: Espinoza, R. Realidad y tiempo en Zubiri Granada: Comares, pp. II-XX.

Gracia, D. (2009). Zubiri en los retos actuales de la antropología. Cuadernos Salmantinos de Filosofía, 36, pp. 103-152.

Guzmán, I. (1984). La técnica en Zubiri. Verdad y vida, 16, pp. 57-70.

Heidegger, M. (1975). La pregunta por la cosa. Buenos Aires: Alfa.

Heidegger, M. (1996). ¿Qué es metafísica? y otros ensayos. Buenos Aires: Fausto.

Heidegger, M. (2000). Ser y tiempo. Santiago de Chile: Editorial Universitaria.

Heidegger, M. (2003). Aporte a la filosofía. Acerca del evento. Buenos Aires: Almagesto.

Heidegger, M. (2006). Prolegómenos para una historia del concepto de tiempo. Madrid: Alianza.

Kant, I (2004). Crítica de la razón pura. Madrid: Alfaguara.

Laín Entralgo, P. (1991). Cuerpo y alma. Estructura dinámica del cuerpo humano. Madrid: Espasa-Calpe.

Laín Entralgo, P. (1995). Alma, cuerpo y persona. Madrid: Galaxia Gutenberg.

López Quintás, A. (1985). La realidad humana, según Xavier Zubiri. Revista Agustiniana, 26, pp. 425-450.

Marquínez, G. (2006). "Realidad", historia de una palabra desde sus orígenes latinos hasta Zubiri. Cuadernos Salmantinos de Filosofía, 33, pp. 145-180. 
Nicolás, J. A y Espinoza, R. (eds.). (2008). Zubiri frente a Heidegger. Barcelona: Herder.

Pintor Ramos, A. (1993). Realidad y sentido: desde una inspiración zubiriana. Salamanca: Universidad Pontificia de Salamanca.

Pintor Ramos, A. (1994a). Realidad y verdad: las bases de la filosofía de Zubiri. Salamanca: Universidad Pontificia de Salamanca.

Pintor Ramos, A. (1994b). En las fronteras de la Fenomenología: la noología de Zubiri. Cuadernos Salmantinos de Filosofía, 21, pp. 45-284.

Racionero, Q. (ed.) (1999). Aristóteles. Retórica. Madrid: Gredos.
Zubiri, X. (1980). Inteligencia sentiente. Inteligencia y realidad. Madrid: Alianza.

Zubiri, X. (1982). Inteligencia y logos. Madrid: Alianza.

Zubiri, X. (1983). Inteligencia y razón. Madrid: Alianza.

Zubiri, X. (1984). El hombre y Dios. Madrid: Alianza.

Zubiri, X. (1986). Sobre el Hombre. Madrid: Alianza.

Zubiri, X. (1988). El hombre y Dios. Madrid: Alianza.

Zubiri, X. (1993). El problema filosófico de la historia de las religiones. Madrid: Alianza.
Zubiri, X. (2004). Naturaleza, Historia, Dios, Madrid: Alianza.

Zubiri, X. (2006a). Tres dimensiones del ser humano: individual, social, histórica. Madrid: Alianza.

Zubiri, X. (2006b). Escritos Menores (19531983). Madrid: Alianza.

Zubiri, X. (2008a). Sobre la esencia. Madrid: Alianza.

Zubiri, X. (2008b). Espacio. Tiempo. Materia. Madrid: Alianza.

Zubiri, X. (2014). Cursos universitarios. Volumen IV. Madrid: Alianza. 